DOI: 10.1515/auseb-2015-0006

\title{
Bankruptcy Prediction: A Survey on Evolution, Critiques, and Solutions
}

\author{
Gergely FEJÉR-KIRÁLY \\ Department of Economics, Faculty of Economics and Human Sciences \\ Sapientia-Hungarian University of Transylvania, Miercurea Ciuc \\ e-mail: fejerkiralygergely@sapientia.siculorum.ro
}

\begin{abstract}
After the economic crisis and the BASEL agreement, the bankruptcy prediction research has evolved substantially due to its importance in corporate finance. This paper summarizes the short history of bankruptcy prediction from the beginning until quite recently. First, it presents a short summary of bankruptcy prediction evolution pointing to the most used models. Then, it provides a summary of the most cited papers that discuss the evolution of bankruptcy prediction and of those papers that have contributed to bankruptcy prediction. Finally, it summarizes some critiques about bankruptcy prediction that the literature has formulated over time and provides some suggestions for future research on bankruptcy prediction.
\end{abstract}

Keywords: failure prediction, parametric modelling, non-parametric modelling, bankruptcy

JEL Classification: G33 - Bankruptcy, liquidation

\section{Introduction}

Bankruptcy is not a desired situation. For every person who is in contact with a company (creditor, owner, and employee), the bankruptcy process is extremely costly. For these stakeholders, the prediction and prevention is very important; they need a less expensive alternative like the reorganization of the company. Bankruptcy also has a social drawback. If a company goes bankrupt, its employees will lose their job. It is also possible that other companies that are in commercial relation will follow in bankruptcy if their activities depend on one another. In this case, the bankruptcy has a contagious effect (Doumpos \& Zopoudinis, 1999). Due to this, most publications and research efforts in the field of bankruptcy prediction are based on testing and developing models that are more accurate on firm failure prediction.

Bankruptcy models are of two types: parametric and non-parametric. The most used parametric models are the multivariate discriminant analysis (MDA) and 
logistic analysis (LA). The multivariate discriminant analysis classifies companies into two groups: healthy and bankrupt companies. The classification is based on the companies' financial characteristics, which are calculated with financial ratios that constitute the variables of the model. The discriminant score allows the classification of the two groups of companies. The difference between logistic analysis and MDA is that the logistic analysis requires logistic distribution (Lo, 1986). Logistic analysis takes into account the failure probability of a company. The parametric models focus on symptoms of bankruptcy and could be univariate and multivariate whose variables are mainly financial ratios (Andan \& Dar, 2006).

The most popular non-parametric models are artificial neural networks (ANN), hazard models, fuzzy models, genetic algorithms (GA) and hybrid models, or models in which several of the former models are combined. The non-parametric models are mainly multivariate and depend heavily on computer technology (Andan \& Dar, 2006). ANN models are able to learn and adapt, form a data set, and they have the ability to capture non-linear relationships between variables. These features are the main advantages of these models. Their weakness lies in the fact that they cannot explain causal relationships among their variables (i.e. financial ratios), which constrains their application to management problems (Lee \& Choi, 2013).

The most cited survey papers in the bankruptcy literature are Balcaen and Ooghe (2004) and Bellovary et al. (2007). These papers focus mainly on parametric modelling. Balcaen and Ooghe (2004) summarize the causes that led bankruptcy prediction to evolve. Also they give an overview on six problems concerning classical statistical methods in bankruptcy prediction. These problems are related to: assumptions on the dichotomous variable, the sampling method, stationarity assumptions and data instability, selection of independent variables, use of accounting information and the time dimension (Balcaen \& Ooghe, 2004). Bellovary et al. (2007) contributes to the bankruptcy literature by summarizing more than 160 papers between 1930 and 2004. The paper contains a table that groups the studies according to the field of application, model type with number of the used factors, and model accuracy. Another author, Kirkos (2015), focuses mainly on artificial intelligence papers ${ }^{1}$ published between 2009 and 2011 by using systematic literature review.

This paper contributes to the literature on bankruptcy failure by presenting a summary of the most relevant survey papers in the bankruptcy literature and by complementing it with more recent papers that have contributed to bankruptcy prediction modelling. In this way, the paper provides practitioners an overview of the main problems. In addition, it provides a summarized description of bankruptcy research regarding modelling and applications by pointing to the main publications in this field.

1 This author studied 119 papers, out of which he studied 42 in depth. All studied papers are related to the usage of artificial intelligence. 
The remainder of this paper is organized as follows. Section 2 briefly summarizes the evolution of bankruptcy prediction. Section 3 provides a summary of the most cited papers that discuss the evolution of bankruptcy prediction and of those papers that have contributed to bankruptcy prediction. Section 4 summarizes some critiques about bankruptcy prediction that the literature has formulated over time and provides some suggestions for future research on bankruptcy prediction. Section 5 concludes.

\section{Evolution of Bankruptcy Prediction}

Balcaen and Ooghe (2004) studied the 35 years of bankruptcy prediction. They found six causes that have made bankruptcy prediction develop in time:

1. The stakeholders of a company are put to high costs if the company goes bankrupt. The need of a less costly method was wanted.

2. Because of negative economic trends or stocks, many companies become increasingly vulnerable to failure and become bankrupt.

3. The financial information of companies becomes public what has helped bankruptcy prediction a lot.

4. The appearance of new papers based on imperfect markets and information asymmetry.

5. The need of getting better reports on financial health. The independent auditor can make a good summary of a company's health, but it cannot predict bankruptcy; that can be made only by modelling.

6. The BASEL agreements resulted in that further analysis were conducted aiming for new models; in this case, the capital can be divided optimally.

Fitzpatrick was the first who studied bankrupt and non-bankrupt firms' financial ratios. In his paper, he compared 20 companies' financial ratios, and found that there are significant differences between bankrupt and healthy firms, mainly between liquidity, debt, and turnover ratios (Fitzpatrick, 1932). Smith and Winakor (1935) were the first who studied the financial ratios in pairs. Their research is based on 183 bankrupt companies. Beaver (1966) found out that 30 financial ratios are relevant in distinguishing bankrupt companies from nonbankrupt ones, but, in the end, with the use of cash flow and total asset ratio the accuracy of the model was $90 \%$ before one year of bankruptcy. His result was based on univariate discriminant analysis, while the sample he used was based on 79 pairs of companies. We mention Chudson (1945), who found out that industryspecific models are more appropriate than general applications across industries.

The first multivariate statistical model is linked to Altman from 1968. Altman had the idea that univariate modelling is not enough for predicting bankruptcy. Using multivariable modelling, he created the model known as the Altman model. 
Since that, his model has been well-known and used as benchmark (Bellovary et al., 2007). Altman used 33 pairs of firms (bankrupt and non-bankrupt), studying their financial ratios for 18 years with multivariate discriminant analysis (MDA) (Altman, 1968). The Altman model is based on five financial ratios and has an accuracy of 95\%. Altman developed his model, known as ZETA model, which is used even today in predicting financial failure (Altman et al., 1977). The new model contained six financial ratios (from these ratios, one was the size of the firm). The model was based on examining 58 pairs of companies for 16 years, and its accuracy was $96 \%$.

Since Altman, many researchers have used the discriminant analysis, making changes, integrating or substituting new ratios which were significant on different samples and business cultures. Some researchers used corrections with industry averages, and as a result they concluded that these models have better accuracy in predicting bankruptcy. Such well-known models were developed by Deakin in 1972, Blum in 1974, Springate in 1978, and Fulmer in 1984. Deakin used 14 financial ratios, from which four were cash-flow-based ratios. Blums' model used accounting ratios and their change in time.

Since the 1980s, a new model has been developed: the logistic regression analysis. The model was developed by Ohlson. He used the financial data starting from 1970 to 1976. The database contained 105 bankrupt and 2,058 non-bankrupt companies. The uniqueness of this model is that it does not take into consideration what the MDA proposes: the normal distribution of the variables does not let the dummy variables be used; secondly, the variance and covariance matrix must be the same in the case of bankrupt and non-bankrupt firms. Finally, one of the weaknesses of the MDA is that it does not predict the probability of failure (Ohlson, 1980). Ohlson was the first who managed to show a negative relation in the size of companies. We must mention Zmijewski, who published his research results in 1984 using probit modelling (Zmijewski, 1984). Zmijewski used 40 bankrupt and 800 healthy firms in the period of 1970-1978. His sample was made of unequal data, increasing the rate between a bankrupt and a non-bankrupt firm from 1:1 to 1:20. Unfortunately, these models did not evolve because their hard and complex usage (Bellovary et al., 2007). With the appearance of these two types of models (logit and probit modelling), the number of papers raised, mostly because many papers made comparison between MDA and logit analysis. The aim of the papers was to study which model had better accuracy based on different variables and data samples. The logistic regression analysis is more often used because it does not need the normal distribution of the variables and the covariance matrix does not need to be equal. One of the biggest disadvantages of the logistic analysis is the problem of multi-colinearity between the variables. This problem can be resolved with using principal component analysis. The next table summarizes the important milestones in bankruptcy prediction, showing which model is from parametric family or non-parametric family. 
Table 1. Important milestones in bankruptcy prediction

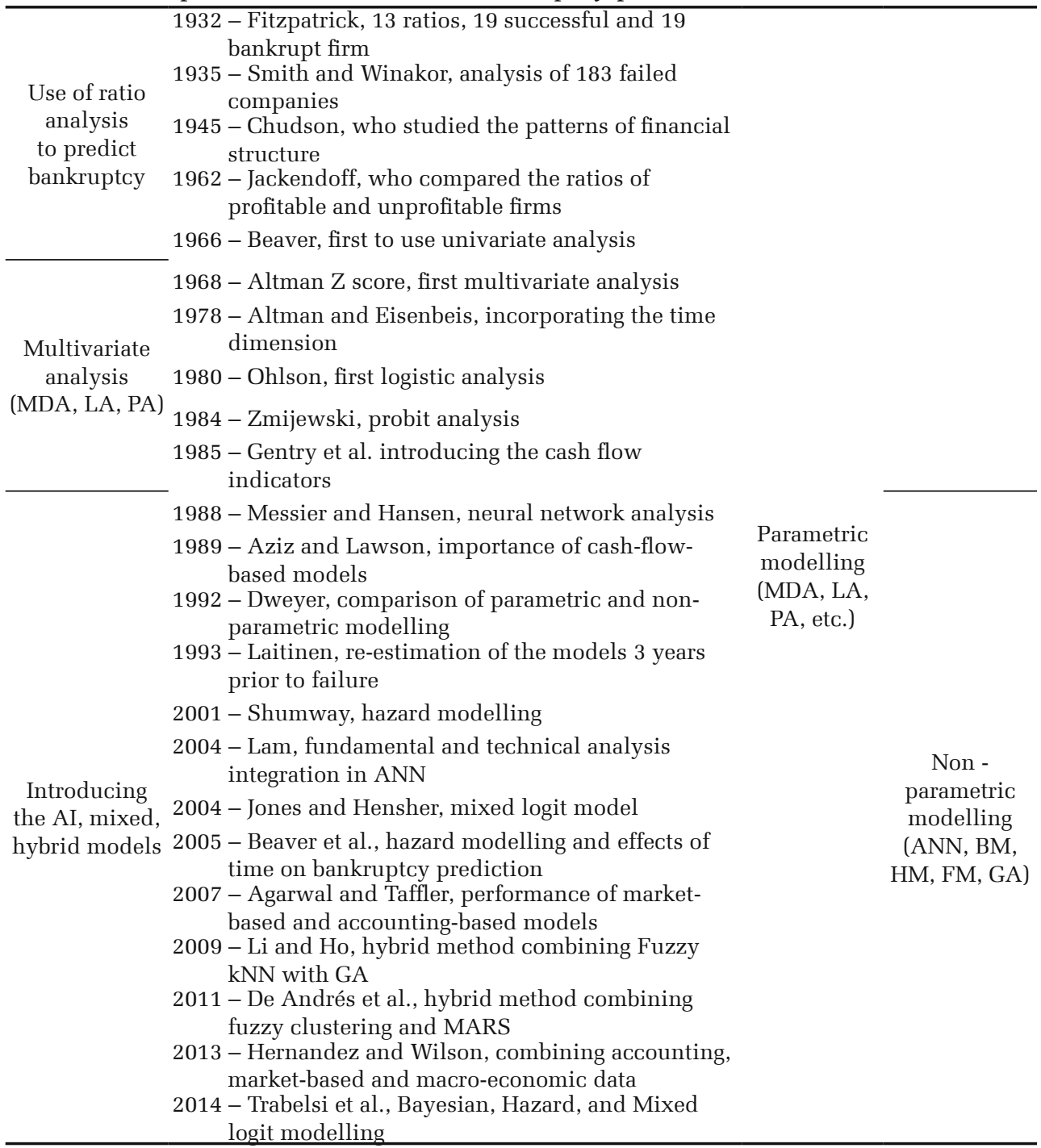

Source: own editing based on Balcaen \& Ooghe, 2004, Bellovary et al., 2007, Kirkos, 2015. Abbreviation used: MDA - multi-discriminant analysis, LA - logistic analysis, PA - probit analysis, HM - hybrid model, FM - fuzzy method, GA - genetic algorithm, ANN - artificial neural network, $\mathrm{BM}$ - Bayesian method, AI - artificial intelligence.

Since the 1990s, the informatics technology has evolved a lot, helping artificial intelligence and managerial systems. A new family of bankruptcy modelling was born: the analysis of neural network (the ANN is a non-parametric modelling). The use of neural networks in bankruptcy prediction is linked to Messier and 
Hansen (1988), who were followed by many others (in Bellovary et al., 2007) such as: Raghupathi et al. (1991), Coats and Fant (1993), Guan (1993), Tsukuda and Baba (1994), and Altman-Marco-Varetto (1994). The analysis of neural network performs a classification; the neurons are nodes with weighted interconnections organized in layers. In the input layer, each node receives information about the company's financial situation and converts into single output. This output is accepted as a classifying decision or re-transmitted till decision is accepted. The acceptance is based on pre-established criteria (Virág \& Kristóf, 2005). The ANN contains many other methods: backpropagation (Dwyer, 1992), SOF-self organizing map (Alam et al., 2000).

Beside the neural network analysis, many other models arise from the nonparametric group like hybrid modelling. These models are the use of two other models either parametric or/and non-parametric (for example MDA and ANN) (Lee et al., 1996). Genetic algorithm works as a stochastic search technique to find out if a company goes bankrupt or not (Varetto, 1998). Other non-parametric models are: genetic programming (Etemadi et al., 1990), modelling based on "rough test" theory (Dimitrias et al., 1999), Bayesian, Hazard, Fuzzy, and Data Envelopment Analysis (DEA).

Many publications were born with the aim of comparing these models or of making a new one, always aiming at maximum accuracy. After 2005, the artificialintelligence-based models are more frequent beside the hybrid models. The paper published by Premachandra et al. (2009) compares LR and DEA. The authors concluded that the DEA models have a better accuracy predicting bankruptcy (accuracy between $84 \%$ and $89 \%$ ), but the LR is more accurate in predicting healthy firms (accuracy between $69.3 \%$ and $99.47 \%$ ). The DEA model was better in estimating bankruptcy based on out-of-sample data $(74 \%-86 \%$ in the case of DEA) (Premachandra et al., 2009).

Verikas et al. (2010) make a review of hybrid modelling and ensemble-based soft computing techniques applied in bankruptcy prediction. The paper presents the most relevant publications in this area (Verikas et al., 2010 - see Table 2 on p. 1006).

An interesting approach is made in the paper published by Korol and Korodi (2011), who use fuzzy logic modelling. The model is built up on the financial data of 132 companies (107 non-bankrupt and 25 bankrupt). They compared two models. The first model is constructed with static financial ratios and the second model is based on the statics and dynamics of financial ratios. The accuracy is better in the second model with 1.85 percentage points $-88.9 \%$. The models containing the dynamics of financial variables have a better accuracy $(81.48 \%)$ even in the case of predicting bankruptcy 3 years in advance (Korol \& Korodi, 2011).

The hazard modelling is another used method of predicting bankruptcy. Gupta et al. (2014) studied the use of a discrete-time hazard model on the data base of 385,733 non-bankrupt and 8,162 bankrupt SMEs. The uniqueness of the paper is 
that it develops three hazard models for micro-, small-, and medium-sized firms. The accuracy is between $74.14 \%$ and $76.10 \%$. Also, the authors concluded that the financial reports do not provide sufficient information about the default of the micro-firms (Gupta et al., 2014).

Nowadays, 3 major groups of modelling are used in bankruptcy prediction: Bayesian, Hazard, and Mixed Logit (Trabelsi et al., 2014). The accuracy and effectiveness was tested by Trabelsi et al. (2014) in their paper, and they concluded as result that the Bayesian model has the smallest misclassification if the optimal cut of point was predicted on the learning sample.

Besides the artificial intelligence, there are still further studies that try alternative models in bankruptcy prediction. Ming Xu and Chu Zhang (2009) compare statistical-based models with market-based models like the option pricing model. The data used are from 3,510 companies' financial data from the Tokyo exchange market. The authors concluded that in the case of Japanese companies the option price modelling has a better prediction capability. Secondly, the statistical model together with the option price model has a greater accuracy. The authors mention the fact that the Japanese culture diverges form other business cultures because of the Keiretsu structure (Xu \& Zhang, 2009).

\section{Literature Review of Bankruptcy Prediction}

This section tries to summarize the main literature review in bankruptcy prediction and the formulated critiques and problems conceived in earlier papers that should be resolved, improving the model prediction accuracy.

Bankruptcy prediction models have become increasingly complex with the development of computing techniques. However, there is no generally accepted bankruptcy prediction model (Constand \& Yazdipour, 2011). This is because there is no general definition of bankruptcy. The papers that aim to develop a model with statistical analysis have a different point of view on the bankruptcy term (Bellovary et al., 2007). These papers can be divided into two categories:

(i) Bankruptcy is seen as a legal procedure and the companies have already taken a legal action.

(ii) Bankruptcy is viewed as a financial distress in the sense that companies cannot meet their payment obligations. In these situations, the companies are not seen as bankrupt because they still have the chance of being reorganized and to continue their activities.

Based on these two categories, we can see that the first group includes companies that are under a legal action whose final step is their liquidation. The second point of view is more likely a short-term financial distress, which can be resolved by grouping the payment obligations under legal supervision. These two points of 
views differ from each other. There should be made some investigation based on two data samples: the first sample based on eventually liquidated companies and the second sample based on companies with financial problems (financially distressed). These two groups can be compared in time before going into bankruptcy to see the differences. This is hard to resolve because financially distressed companies tend to be similar to the healthy ones regarding long-term debt ratios.

The paper of Balcaen et al. had the aim to show the strengths and weaknesses of univariate, risk-index-based models, multivariate discriminant models, and conditional probability models. Further, they show the lack of the logistic regression analysis including logistic regression, probit, and linear probit models. As a conclusion, the authors mentioned several problems and solutions related to the classical statistical methods of MDA and conditional probability models:

- the use of dichotomous dependent variables which are contrary to the business reality;

- there are problems on sampling methods, non-stationarity, and data instability, which result in poor predictive abilities over time;

- the use of macroeconomic and industry-specific variables help the predictive accuracy of the models;

- the selection of the variables is made arbitrarily - the variables may be selected within the theoretical framework;

- the time dimension problem, the classical statistical models ignore the changes over time (Balcaen \& Ooghe, 2004).

Bellovarys' paper (2007) presents in details the most important papers in bankruptcy prediction. The authors present 165 papers starting from 1966 to 2004. From these papers, 43 studies compare two or more models. They did not account for those papers that replicate a model. In the appendix, it is presented the field used in different prediction models. From this point of view, the models can be organized into three major groups: general (the models are based on samples from different industries), banks, and industry-specific models. The models can be divided into two major groups: parametric and non-parametric groups. In the parametric group, the most frequently used are the multi-discriminant analysis and the logistic regression. The main models used in the non-parametric group are the artificial neural network, the Bayesian models, the Hazard models, the Fuzzy models, the Genetic Algorithm, and the Hybrid models. Most of the models were applied for general use, but with time bankruptcy prediction became more industry-specific due to the many publications that had showed that accuracy could be increased if industry-specific data sets were used (Bottazzi et al., 2010; Virág et al., 2013). Many research papers (such as those of: Martin, 1977; Santomero \& Vinso, 1977; Rose \& Kolari, 1985; Pantalone \& Platt, 1987; Martin-del-Brio \& Serrano-Cinca, 1995; Alam et al., 2000) used data from banking financial statements for predicting bank failure. 
Till the 1990s, the MDA was the most frequently used modelling, but after that the neural network modelling came as first because of the higher accuracy rate what even today is still disagreed upon (Bellovary et al., 2007). The numbers used in the models differ from one another. The most used variable in a model is 57 , but its prediction accuracy is not better than that of the less frequently used variables (Bellovary et al., 2007). The high number of variables used does not mean that a model is better (Jones, 1987). The average number of used variables is 8 . The most frequently used financial ratio in models is the return on assets, general liquidity, and working capital on total assets. The cash-flow-based ratios became attractive later, but these ratios became intensively used (this is normal if we take in consideration that bankruptcy is the result of the payment failure of a company, which means that they do not have cash to pay). One of the most used cash flow variable is the cash flow based on assets (Bellovary et al., 2007).

The accuracy of the models has increased in time, but the difference between the minimal and maximal accuracy has become wider. The most accurate models are the neural networks, but the results of these models are complicate to interpret (there exist models with $100 \%$ accuracy). These models are followed by MDA and logistic regression.

With the evolution of artificial intelligence, the use of non-parametric models has become more and more frequent. Other models in these groups are: neural networks, genetic algorithms, decision trees, support vector machines, k-nearest neighbour, fuzzy expert system, and hybrid models.

A review of literature in artificial intelligence models used in bankruptcy prediction can be found in Perez (2006), Ravi (2007), Verikas et al. (2010), and Kirkos (2015). Perez's paper reviews 30 papers and the use of NN models and its weaknesses (Perez, 2006). Ravi (2007) makes a summary comprising a longer period of time (1968-2005) in this field. Verikas et al. (2010) made further corrections of calculation, which helped the creation of new hybrid models.

Kirkos (2015) is different from the others: firstly, because he is the first to use the Systematic Literature Review technique; secondly, because the 42 papers published between 2009 and 2011 are taken from highly reputed papers (Thomson-Reuter database, with impact factors higher than 0.5); thirdly, because he uses a holistic approach in his paper concentrated around six major axes: first, the aim of bankruptcy prediction research in the field of artificial intelligence, secondly, methods used in classification, thirdly, the used models and the used factor with their effects, fourthly, the type of used data and the characteristics of used data, fifthly, which data set was finally selected, and lastly what the conclusions and findings were. The accuracy of the studied models was between $72 \%$ and $100 \%$. Half of the studies had an accuracy of $81-90 \%$, while $29 \%$ of the papers exceeded the accuracy of $91 \%$. One of the final conclusions was - as in Altman et al. (1995) and Dimitras et al. (1999) - that bankruptcy prediction 
accuracy decreased if the data originated from more than 2 or 3 years before the bankruptcy; this is due to the presumption that bankruptcy is a process, not an event. These results are opposite to the presumptions proposed by other researchers that the financial ratios must be taken as time series.

From Kirkos's study, we can conclude that the most frequently used models for accuracy benchmark for the neural networks are logistic regression and discriminant analysis. Many of these studies concluded that the neural network has a better predictability if a smaller sample is used; in the case of big data samples, the learning process can be a problem (over learning) (Chen, 2011; Lee et al., 2005). To this fact, Du Jardin and Severin (2011) gave an explanation that there are companies that are survivors because of the diversification of their activity, and if they are included in big data samples they will occur more frequently, so the classification error is bigger in the learning process.

\section{Critiques Formulated and Suggestions for Future}

The critiques formulated in bankruptcy prediction are formulated to the use of financial ratios, sampling methods, the lack of non-financial variables, and the use of the period. The time series used is an important factor in predicting failure. The researches did not prove that the use of time series variables is better than the one-year variables before bankruptcy. The time period should be carefully chosen because if there are economic changes, besides the financial ratios, the model should contain important macroeconomic variables too.

The most frequent variable used in bankruptcy prediction is the use of financial ratios. This is due to the publicity of the financial data and because there is a high motivation to get more accurate models. The importance of accuracy comes from cost efficiency and capital optimization. The type I and type II errors have significant disadvantages for investors. Finally, the financial ratio database is simple to use in statistical modelling and has high accuracy as seen in many publications, close to and even reaching 100\% (Bellovary et al., 2007; Balcaen \& Ooghe, 2004; Kirkos, 2015). There are many critiques formulated to the use of financial variables in bankruptcy prediction. One of them is the use of dichotomous variables. In real business life, the corporate failure is not a clearly separated situation. Another issue, due to the usage of financial ratio, is the distribution of irregularities in the case of financial ratios (Martikainen et al., 1995). Martikainen et al. (1995) give transformation suggestions for ratio classification. In their paper, the authors found that the distribution irregularities have a significant effect on financial ratio classification. Altman and Sabato (2007) used logarithmic transformation for financial variables, increasing this way the information value of each variable. 
For the same problem, Blanco et al. (2012) used hyperbolic tangent transformation for five financial variables.

Critiques are formulated to the use of only financial variables. The critiques are driven from the opinion that bankruptcy is the effect of many variables, not only financial ones. Bankruptcy is the effect of misleading (human factor) and economic situation. In this way, the use of only financial variables is not enough.

Many papers try to use financial variables with non-financial variables. Constand and Yazdipour (2011) argue that most of the researches leave out the human factor from the variables. Their solution is to use the cognitive psychology and neuron science, which have already changed our perception and our knowledge on financial decision behaviour. There are results that show that managers tend to take higher risk in investing in a high-risk project if they find that project interesting (Constand \& Yazdipour, 2011). In their paper, the authors make a short review of those papers that studied the entrepreneurial behaviour, pointing out that the human factor is relevant in starting a company and it is a factor that influences bankruptcy (Kahneman \& Lovallo, 1993).

The paper by Altman et al. (2010) studied the importance of non-financial variables (default events on a monthly basis are available from government agencies) in SME business failure besides the financial ratios (data sample: almost 6 million SMEs). Their conclusion was that the non-financial variables improved prediction accuracy by up to $13 \%$. The same results were concluded in the paper of Gupta et al. (2014). Their research used hazard function with financial variables and non-financial variables. The non-financial variables used were the firms' audit information, compliance information, the firms' age, their accounts filing history, and the legal actions taken by lenders. The authors used a heterogeneous panel of 8,162 failed and 385,733 non-failed UK SMEs between 2000 and 2009. The results showed that micro-companies should be treated separately in bankruptcy prediction. The use of only financial ratios does not provide enough information on the default (Gupta et al., 2014).

Another group of studies developed bankruptcy prediction models which use besides financial ratios market-based ratios and macroeconomic variables, combining these into a model (Hernandez and Wilson, 2013). The authors used from 130 variables 3 financial ratios and 2 macroeconomic variables, and they compared the results in a panel logit model. The results were that the use of macroeconomic variables gives the model a better accuracy than the models that use only financial or financial and market variables (Hernandez \& Wilson, 2013). In their paper, $\mathrm{Xu}$ and Zhang (2009) compared accounting variables, option pricing theory-based variables and other economic-variables-based models. They found out that with the model that combines accounting variables with option pricing variables predictability is higher than with the model only based on accounting variables (Xu and Zhang, 2009). 
There are a few papers that study the importance of legal acts on bankruptcy. These papers find that decision makers and laws can generate modification in bankruptcy prediction - see the papers of Dewaelheyns \& van Hulle (2008), Laitinen (2011), and García \& Sanguinetti (2014).

\section{Conclusions}

The present paper summarizes the short evolution of bankruptcy prediction and the main critiques made on modelling and prediction of bankruptcy, as well as it summarizes the future research avenues recommended in these studies. The critiques are based on three important survey papers, namely Balcaen and Ooghe (2004), Bellovary et al. (2007), and Kirkos (2015), where the latter is a review of the most important papers in artificial intelligence and theoretical approaches.

A final conclusion can be made that, based on the reviewed papers, bankruptcy prediction still has new, unconquered fields because of the diversity of business culture (see Xu \& Zhang, 2009), on the one hand, and due to its complexity, on the other hand, there is an area that has not been properly explored. The knowledge on managerial behaviour can be used in bankruptcy predictability.

Another possible avenue for future research is to statistically classify the different models by their inputs (number of ratios used, type of ratios used, cultural characteristics, models used, industry type, macroeconomic factors, and other relevant independent variables taken from the models) and use the accuracy of that model as a dependent variable. We believe that this way it is possible to obtain further information on why some models are better than others.

\section{References}

Adnan, M.; Dar, A. H. (2006). Predicting corporate bankruptcy: where we stand? Corporate Governance 6(1): 18-33.

Agarwal, V.; Taffler, R. (2008). Comparing the performance of market-based and accounting-based bankruptcy prediction models. Journal of Banking and Finance 32: 1541-1555.

Alam, P.; Booth, D.; Lee, K.; Thordarson, T. (2000). The use of fuzzy clustering algorithm and self-organizing neural networks for identifying potentially failing banks: an experimental study. Expert Systems with Applications 18: 185-199.

Altman, E. I. (1968). Financial ratios, discriminant analysis and the prediction of corporate bankruptcy. The Journal of Finance 23(4): 589-609. 
Altman, E. I.; Sabato, G. (2007). Modelling credit risk for SMEs. Evidence from US Market. A Journal of Accounting, Finance and Business Studies. 43(3): 332-357. Altman, E. I.; Haldeman, R.; Narayanan, P. (1977). ZETA analysis, a new model for bankruptcy classification. Journal of Banking and Finance 1(1): 29-54.

Altman, E. I.; Wilson, N.; Sabato, G. (2007). The value of non-financial information in SME risk management. The Journal of Credit Risk, 6(2): 1-40.

Balcaen, S.; Ooghe, H. (2004). 35 years of studies on business failure: an overview of the classical statistical methodologies and their related problems. Working paper. Ghent University, June, 248: 1-62.

Beaver, W. H.; McNichols, M. F.; Rhie, Jung-Wu (2005). Have financial statements become less informative? Evidence from the ability of financial ratios to predict bankruptcy, Review of Accounting Studies 10: 95-122.

Bellovary, J.; Giacomino, D.; Akers, M. (2007). A review of bankruptcy prediction studies: 1930-present. Journal of Finance Education 33: 1-42.

Blanco, A.; Irimia, A.; Dolores, M. O. (2012). The prediction of bankruptcy of small firms in the UK using logistic regression. Análisis Financiero 118: 32-40.

Bottazzi, G.; Grazzi, M.; Secchi, A.; Tamagni, F. (2010). Financial and economic determinants of firm default. FINNIV Discussion Paper. pp. 1-29.

Camerer, C.; Lovallo, D. (1999). Overconfidence and excess entry: An experimental approach. The American Economic Review 89(1): 306-318.

Chen, M. Y. (2011). Bankruptcy prediction in firms with statistical and intelligent techniques and comparison of evolutionary computation approaches. Comput. Math. Appl. 62: 4514-4524.

Constand, L. R.; Yazdipour, R. (2011). Firm failure prediction models: a critique and a review of recent developments, advances in entrepreneurial finance: with applications from behavioral finance and economics. Springer Science and Business Media. pp. 185-204.

Chudson, W. (1945). The pattern of corporate financial structure. New York: National Bureau of Economic Research.

Dewaelheyns, N.; van Hulle, C. (2008). Legal reform and aggregate small and micro business bankruptcy rates: evidence from the 1997 Belgian bankruptcy code. Small Business Economics 3: 409-424.

Dimitras, A.; Zanakis, S.; Zopounidis, C. (1996). A survey of business failures with an emphasis on prediction methods and industrial applications. European Journal of Operational Research 90: 487-513.

Dimitras, A. I.; Slowinski, R. S.; Zoupounidis, C. (1999). Business failure prediction using rough sets. European Journal of Operation Research 114(2): 263-280.

Doumpos M.; Zopoudinis C. (1999). A multicriteria discrimination method for the prediction of financial distress: the case of Greece. Multinational Finance Journal 3(2): 71-101. 
Dwyer, M. (1992). A comparison of statistical techniques and artificial neural network models in corporate bankruptcy prediction. Ph.D. dissertation. University of Wisconsin-Madison.

Fitzpatrick, P. (1932). A comparison of the ratios of successful industrial enterprises with those of failed companies. Washington: The Accountants' Publishing Company.

Fulmer, J.; Moon, J.; Gavin, T.; Erwin, M. (1984). A bankruptcy classification model for small firms. Journal of Commercial Bank Lending July: 25-37.

García-Posada, M.; Mora-Sanguinetti, J. S. (2014). Are there alternatives to bankruptcy? A study of small business distress in Spain. SERIEs 5: 287-332.

Gupta, J.; Gregoriou, A.; Healy, J. (2014). Forecasting bankruptcy for SMEs using hazard function: To what extent does size matter? Review of Quantitative Finance and Accountings, Springer Science+Business Media. pp. 1-25.

Hernandez, M. T.; Wilson, N. (2013). Financial distress and bankruptcy prediction among listed companies using accounting, market and macroeconomics variables. International Review of Financial Analysis 30: 394-419.

De Andrés, J.; Lorca, P.; Javier de Cos Juez, F.; Sánchez-Lasheras, F. (2011). Bankruptcy forecasting: A hybrid approach using Fuzzy c-means clustering and Multivariate Adaptive Regression Splines (MARS). Expert System with Applications 38: 1866-1875.

Jones, F. (1987). Current techniques in bankruptcy prediction. Journal of Accounting Literature 6: 131-164.

Kahneman, D.; Lovallo, D. (1993). Timid choices and bold forecasts. A cognitive perspective on risk taking. Management Science 39(1): 17-31.

Kirkos, E. (2015). Assessing methodologies for intelligent bankruptcy prediction. Artificial Intelligence Review 43: 83-123.

Koro, T.; Korodi, A. (2011). An evaluation of effectiveness of Fuzzy logic model in predicting the business bankruptcy. Romanian Journal of Economic Forecasting 3: 92-107.

Laitinen, E. K. (2011). Assessing viability of Finnish reorganization and bankruptcy firms. European Journal of Law and Economics 31: 167-198.

Lee, K. C.; I. Han; Y. Kwon (1996). Hybrid neural network models for bankruptcy predictions. Decision Support Systems 18(1): 63-72.

Lee, K.; Booth, D.; Alam, P. (2005). A comparison of supervised and unsupervised neural networks in predicting bankruptcy of Korean firms. Expert System Application 29: 1-16.

Lee, S.; Choi, W. S. (2013). A multi-industry bankruptcy prediction model using back-propagation neural network and multivariate discriminant analysis. IExpert System with Applications 40: 2941-2946.

Lo, A. W. (1986). Logit versus discriminant analysis. A specification test and application to corporate bankruptcies. Journal of Econometrics 31: 151-178. 
Martikainen, T.; Perttunen, J.; Yli-Ollie, P.; Gunasekaran, A. (1995). Financial ratio distribution irregularities: implication for ratio classification. European Journal of Operational Research 80: 34-44.

Martin, D. (1977). Early warning of bank failures: A logit regression approach. Journal of Banking and Finance 1: 249-276.

Martin-del-Brio, B.; Serrano-Cinca, C. (1995). Self-organizing neural networks: The financial state of Spanish companies. Neural Network in the Capital Markets. In: Refenes (ed.), Chichester: Wiley, pp. 341-357.

Messier, Jr., W.; Hansen, J. (1988). Inducing rules for expert system development: an example using default and bankruptcy data. Management Science 34(12): 1403-1415.

Ohlson, J. A. (1980). Financial ratios and the probabilistic prediction of bankruptcy. Journal of Accounting Research 18(1): 109-131.

Pantalone, C.; Platt, M. (1987). Predicting commercial bank failure since deregulation. New England Economic Review, Federal Reserve Bank of Boston July-August, pp. 37-47.

Perez, M. (2006). Artificial neural network and bankruptcy forecasting: a state of the art. Neural Comput. Appl. 15: 154-163.

Premachandra, I. M.; Bhbra, G. S.; Sueyoshi, T. (2009). DEA as a tool for bankruptcy assessment: A comparative study with logistic regression technique. European Journal of Operational Research 193: 412-424.

Ravi, K. P.; Ravi, V. (2007). Bankruptcy prediction in firms and banks via statistical and intelligent techniques - a review. European Journal of Operation Research 180: 1-28.

Rose, P.; Kolari, J. (1985). Early bankruptcy prediction using neural networks: A new tool for predicting bank failures. Decision Sciences 23: 899-916.

Sands, E.; Springate, G.; Var, T. (1983). Predicting business failures: a Canadian approach. CGA Magazine 17: 24-27.

Santomero, A.; Vinso, J. (1977). Estimating the probability of failure for commercial banks and the banking system. Journal of Banking and Finance 1(2): 185-205.

Smith, R.; Winakor, A. (1935). Changes in financial structure of unsuccessful industrial corporations. Bureau of Business Research, Bulletin no. 51. Urbana: University of Illinois Press.

Trabelsi, S.; He, R.; He, L.; Kusy, M. (2014). A comparison of Bayesian, Hazard and mixed logit model of bankruptcy prediction. Computing Management Science January: 1-17.

Vareto, F. (1998). Genetic algorithms applications in the analysis of insolvency risk. Journal of Banking and Finance 22: 1421-1439.

Verikas, A.; Kalsyte, Z.; Bacauskiene, M.; Gelzinis, A. (2010). Hybrid and ensemble-based soft computing techniques in bankruptcy prediction: a survey. Soft Computing 14: 995-1010. 
Virág, M.; Kristóf, T.; Fiáth, A.; Varsányi J. (2013). Pénzügyi elemzés, csődelőrejelzés, válságkezelés. Budapest: Kossuth Kiadó.

Virág, M.; Kristóf, T. (2005). Az első hazai csődmodell újraszámítása neurális hálók segítségével. Közgazdasági Szemle LII(February): 144-162.

$\mathrm{Xu}, \mathrm{M}$.; Zhang, C. (2009). Bankruptcy prediction: the case of Japanese listed companies. Review of Accounting Studies 14: 534-558.

Zmijewski, M. E. (1984). Methodological issues related to the estimation of financial distress prediction models. Journal of Accounting Research 24(Supplement): 59-82. 